\title{
ESTRUTURAÇÃO TECTÔNICA E ANÁLISE DEFORMACIONAL DO SEGMENTO CENTRAL DO CINTURÃO RIBEIRA NA SERRA DA BOCAINA, NOS ESTADOS DE SÃO PAULO E RIO DE JANEIRO
}

\author{
SERGIO HENRIQUE SOUSA ALMEIDA ${ }^{1} \&$ HANS DIRK EBERT ${ }^{2}$ (IN MEMORIAM)
}

\begin{abstract}
Resumo O segmento central do Cinturão Ribeira, constituído de rochas orto- e paraderivadas de médio a alto grau metamórfico, é recortado por expressivos feixes de zonas de cisalhamento dúcteis de direção NE-SW. Este trabalho apresenta os resultados da análise estrutural quantitativa desenvolvida na Serra da Bocaina (SP/RJ), com a finalidade de determinar os regimes tectônicos e deformacionais relacionados à orogênese Neoproterozóica. A deformação penetrativa, bem registrada pela microestrutura das rochas, foi quantificada a partir da análise de grãos de quartzo e feldspato em lâminas delgadas. Foram analisadas 29 amostras de gnaisses, com foliações gnáissica (Sn) e milonítica (Sm), coletadas entre as zonas de cisalhamento Rio Preto (ZCRP) e ArcádiaAreal (ZCAA), através do método de $\mathrm{Rf} / \phi$. As amostras revelaram razões de deformação $\mathrm{R}_{x z}$ entre 2,0 e 5,2 e predomínio de valores baixos a médios $\left(2,0<\mathrm{R}_{\mathrm{xz}}<3,0\right)$. No plano $\mathrm{YZ}$ os resultados variaram entre 1,4 e 3,3. O elipsóide médio, para a área, apresenta relação de dimensões dos semi-eixos X:Y:Z de 1,45:1,1:0,65, que corresponde a um estiramento médio de 45\% em X (sub-horizontal na direção NE-SW), de 10\% em Y (vertical) e um encurtamento de 35\% ao longo de Z (direção NW-SE). O elipsóide geral (regional bulk strain) de deformação finita tem forma oblata $\left(\mathrm{K}_{\mathrm{Flinn}}\right.$ médio de 0,38$)$ e correspondente ao campo do achatamento geral. Os maiores valores de vorticidade (Wk $<0,81$ ) estão próximos às zonas de cisalhamento e no Domínio Paraíba do Sul (DPS), onde predomina transcorrência, ao passo que valores menores $(0,15<\mathrm{Wk}<0,75)$, isto é, com predomínio de deformação coaxial, ocorrem internamente aos domínios Embu (DE) e Juiz de Fora (DJF). A integração dos valores de deformação cisalhante $\gamma$ (gama), estimados entre as zonas ZCRP e ZCAA $(1,3<\gamma<8,9)$, permitiu inferir rejeitos direcionais próximos a $200 \mathrm{~km}$. Os resultados corroboram a observação geral de dois tipos de deformação na área: transcorrência dextral e encurtamento perpendicular às zonas de cisalhamento, materializado através de dobras simétricas e assimétricas, bem como achatamento dos agregados minerais. Isto confirma que o Cinturão Ribeira sofreu uma transpressão dextral, acomodada através da partição da deformação entre estruturas contracionais NW-SE e transcorrentes NE-SW.
\end{abstract}

Palavras-chave: Cinturão Ribeira, Transpressão, Zonas de Cisalhamento, Análise de Deformação, Vorticidade

\begin{abstract}
The central segment of the Ribeira belt in southeastern Brazil comprises orthogneisses and paragneisses of medium to high grade metamorphic conditions, beeing dominated by regional NE-SW trending ductile shear zones. This paper presents the results of structural and strain analysis carried out in the Serra da Bocaina range, bordering region between the states of São Paulo and Rio de Janeiro, with the aim to better constrain the tectonic regime and the nature of the deformational process associated to the orogenic processes. In that area a pervasive strain is well recorded in the microstructures associated to gneissic (Sn) and mylonitic (Sm) foliations. Samples from 29 gneiss outcrops between the Rio Preto (ZCRP) and the Arcádia-Areal (ZCAA) shear zones were analysed using the Rf/ $\phi$ method on quartz and feldspar grains in thin sections. On the main kinematic plane, the samples showed typically low to medium strain ratios $\left(2<\mathrm{R}_{\mathrm{x} z}<3\right)$ and some increasing values reaching 5.2 along the shear zones. On the $\mathrm{YZ}$ plane, $\mathrm{R}_{\mathrm{yz}}$ ranges between 1.0 and 3.3. The average ellipsoid estimated from all samples shows $\mathrm{X}: \mathrm{Y}: \mathrm{Z}$ semi-axes dimensions of 1.45:1.1:0.65, which corresponds to a stretching of $45 \%$ in X (sub-horizontal NE-SW), $10 \%$ in Y (vertical) and a shortening of $35 \%$ in $\mathrm{Z}$ (NW-SE). The overall finite strain ellipsoid (regional bulk strain) shows an oblate shape (medium $\mathrm{K}_{\text {flinn }}$ of 0.38 ) that corresponds to the general flattening field. The highest vorticity values $(\mathrm{Wk}<0.81)$ are found along strike-slip shear zones and in the Paraíba do Sul domain, while coaxial deformations $(0.15<\mathrm{Wk}<0.75)$ predominate inside the Embu and the Juiz de Fora domains. The integration of shear strain values $\gamma(1.3<\gamma<8.9)$ obtained between the ZCRP and ZCAA allows to estimate an overall strike-slip displacement of almost $200 \mathrm{Km}$. The general tectonic model is represented by two types of deformations: dextral strike-slip and shortening perpendicular to the shear zones, which is visible by symmetrical and asymmetrical folds, as well as mineral aggregates flattening. The partitioning between NW-SE contraction and NE-SW transcurrent structures confirms the transpressional tectonic regime in the central segment of the Ribeira Belt, which is compatible to E-W collision.
\end{abstract}

Keywords: Ribeira Belt, Transpression, Shear Zones, Strain Analysis, Vorticity

\begin{abstract}
INTRODUÇÃO
O Segmento Central do Cinturão Ribeira (SCCR) é constituído por rochas orto- e paraderivadas de médio a alto grau metamórfico e é afetado por expressivo feixe de zonas de cisalhamento dúcteis, de caráter cinemático complexo (reverso, oblíquo e transcorrente). Para contribuir com o entendimento dos regimes tectônicos e deformacionais ocorridos, principalmente em termos da magnitude e dos mecanismos da deformação, realizou-se a análise de deformação na Serra da Bocaina, região limítrofe entre os estados de São Paulo e Rio de Janeiro (Figura 1). As escassas informações disponíveis para a quantificação de processos deformacionais no Cinturão Ribeira estão restritas aos trabalhos de Dayan \& Keller (1990),
\end{abstract}

na Zona de Cisalhamento Paraíba do Sul (ZCPS) próximo Três Rios (RJ); Fiori (1997), em granitos nas imediações de Curitiba (PR); Braga \& Ebert (1998) em gnaisses da porção central da Cunha de Guaxupé e Campanha \& Sadowski (2002), nos metassedimentos da região Vale do Ribeira.

A análise de deformação pode ser aplicada a estruturas em escalas diversas, desde mapas geológicos e fotografias aéreas (deflexão de estruturas em zonas de cisalhamento), afloramentos (veios, dobras, falhas, ângulos entre as foliações S-C), amostras macroscópicas (achatamento de seixos) e lâminas delgadas (forma dos grãos minerais e porfiroclastos rotacionados). Como na área estudada a deformação é penetrativa e está registrada 


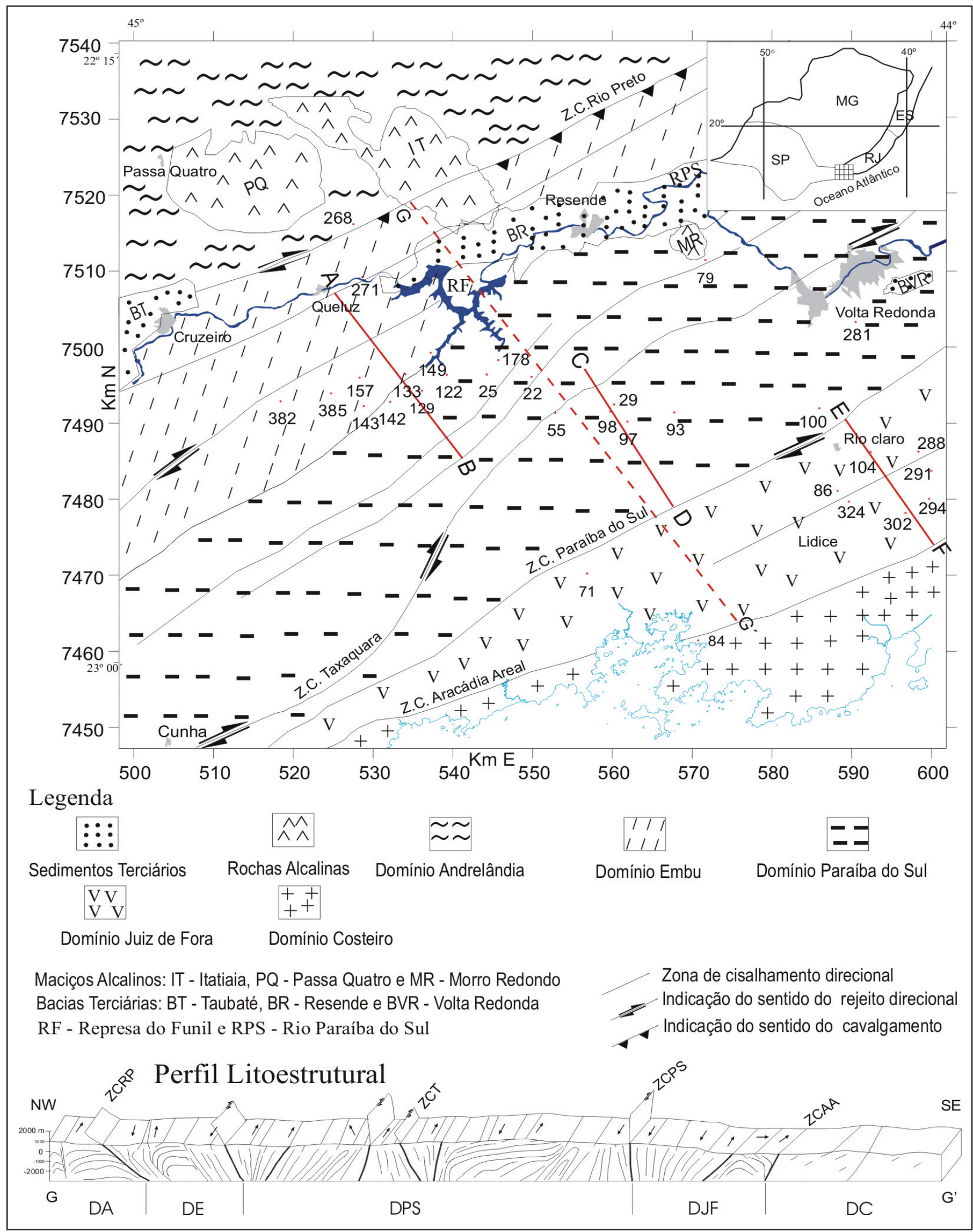

Figura 1 - Compartimentação do Segmento Central do Cinturão Ribeira na região da Serra da Bocaina (Estados de São Paulo e Rio de Janeiro), mostrando os cinco domínios litoestruturais: Andrelândia (DA), Embu (DE), Paraíba do Sul (DPS), Juiz de Fora (DJF) e Costeiro (DC), as principais zonas de cisalhamento (Z.C.), as bacias de Taubaté (BT), Resende (BR) e Volta Redonda (BVR) e as alcalinas de Passa Quatro (PQ), Itatiaia (IT) e Morro Redondo (MR). O mapa litoestrutural contém a distribuição de pontos com análise de deformação (Tabela 1) e localização dos perfis $A B, C D$ e EF utilizados para o cálculo de deslocamento do cinturão orogênico (Figura 6). O perfil litoestrutural $G-G^{\prime}$ ressalta as estruturas Sn e Ln (setas) e a movimentação das zonas de cisalhamento. 
nas microestruturas das rochas, a análise deformacional foi investigada a partir dos grãos minerais em lâminas delgadas, utilizando-se o método de $\mathrm{Rf} / \phi$.

\section{CONTEXTO LITOESTRUTURAL}

Domínios Litoestruturais A região estudada situa-se a sul do Cráton São Francisco, no Segmento Central do Cinturão Ribeira, limítrofe entre os estados de São Paulo e Rio de Janeiro, adjacente à margem continental (Bacia de Santos), sendo delimitada pelos paralelos $22^{\circ} 15^{\prime} \mathrm{S}$ e $23^{\circ} 25^{\prime} \mathrm{S}$ e os meridianos $44^{0} 00^{\prime} \mathrm{W}$ e $45^{\circ} 00^{\prime} \mathrm{W}$, região da Serra da Bocaina. A área foi compartimentada em cinco domínios litoestruturais (Figura 1), a partir de NW para SE, tomando-se por base trabalhos de campo integrados aos dados de literatura geológica (Brandalise et al. 1976, Hasui et al. 1978, Fonseca et al. 1979, Machado Filho et al. 1983, DRM 1983, Castro et al. 1984, Almeida et al. 1993, Fonseca 1998, Heilbron et al. 1999, Dehler \& Silva 1999, Almeida 2000, Nummer 2001).

O Domínio Andrelândia (DA) compreende a extremidade noroeste da área, onde predominam rochas do Grupo Andrelândia (Trouw et al. 1983, Heilbron 1993), de idades Mesoproterozóicas (Söllner \& Trouw 1997), que incluem granada biotita muscovita xistos, granada biotita gnaisses, quartzitos, biotita gnaisses migmatíticos e biotita gnaisses com intercalações de rochas cálciosilicáticas, quartzitos e xistos granatíferos. Associações minerais com granada, cianita e feldspato potássico indicam condições metamórficas de fácies anfibolito alto, de alta pressão.

O Domínio Embu (DE) é constituído por rochas metassedimentares de fácies anfibolito alto a granulito, tais como, biotita gnaisses, sillimanita granada biotita gnaisses, sillimanita granada gnaisses (kinzigitos), xistos quartzo-feldspáticos (com granada e sillimanita), sillimanita quartzitos, rochas cálcio-silicáticas, gonditos (granada-quartzo) e gnaisses anfibolíticos. Subordinamente, ocorrem lentes de ortognaisses granulíticos, com ou sem granadas e ausência de feldspatos potássicos (hiperstênio gnaisses e diopsídio hiperstênio gnaisses). Este domínio contém corpos granitóides e migmatitos que na região de Cunha (SP) registram idades $\mathrm{T}_{\mathrm{dm}}$ entre 2,7 e 1,9 Ga (Tassinari e Sato 1996).

O Domínio Paraíba do Sul (DPS) é caracterizado por metassedimentos de idades Meso- a Neoproterozóicas (Machado et al. 1996), que incluem biotita gnaisses, muscovita biotita gnaisses, biotita (quartzo) xistos e muscovita biotita xistos, quartzitos e muscovita quartzitos, gnaisses anfibolíticos, gnaisses quartzofeldspáticos, mármores e rochas cálcio-silicáticas. Estas rochas encontram-se secionadas por granitóides (Dias Neto et al. 1995, Machado et al. 1996) sin-tectônicos (hornblenda biotita gnaisses e biotita gnaisses), e pós-tectônicos, representados pelos granitos Getulândia, Fortaleza e Arrozal (Almeida et al. 1993, Nummer 2001). As associações mineralógicas são de fácies anfibolito de pressão intermediária e, localmente, essas rochas foram submetidas à fusão parcial, como evidenciado pelos migmatitos e níveis mobilizados de composição granítica.

O Domínio Juiz de Fora (DJF) é constituído essencialmente por ortognaisses de fácies granulito de idades Paleoproterozóicas (Machado et al. 1996), representados por granulitos ácidos a básicos, tais como hiperstênio gnaisse granulitos, diopsídio hiperstênio gnaisse granulitos e biotita hornblenda gnaisse tonalíticos. Biotita hornblenda gnaisses são por vezes granatíferos e de natureza tonalítica, e semelhantes aos ortognaisses do Complexo Quirino (Heilbron et al. 1995), também de idade Paleoproterozóica (Machado et al. 1996). Em menor proporção, ocorrem metassedimentos de fácies anfibolito alto a granulito, tais como sillimanita quartzitos, granada sillimanita gnaisses, granada biotita gnaisses e rochas cálcio-silicáticas. Ocorrem, ainda, granitos e granodioritos, gnaisses quartzo-feldspáticos, leucognaisses e biotita gnaisses de granulação média a porfirói- des. Condições retrógradas para a fácies anfibolito são reveladas pela desestabilização de piroxênio e diopsídio, alterados para hornblenda.

O Domínio Costeiro (DC) contém granitos e granodioritos com freqüentes xenólitos de biotita gnaisse migmatíticos, associados ao Complexo Rio Negro, e biotita gnaisses e biotita hornblenda gnaisses associados ao Complexo Costeiro. Ambos estão migmatizados e milonitizados e têm idades Neoproterozóicas (Machado et al. 1996, Tupinambá et al. 1996). A associação mineralógica mais comum é representada por quartzo + microclínio + plagioclásio + biotita, característica de fácies anfibolito.

Os domínios litoestruturais descritos acima serviram de substrato para as bacias Cenozóicas de Resende, Volta Redonda e extremidade NE da Bacia de Taubaté, constituídas por sedimentos Terciários e Quaternários (Almeida 1976, Riccomini et al. 1987, Hasui et al. 1978 e Mello et al. 1985). Além disso, são comuns na região diques básicos de idade Mesozóica e de intrusivas alcalinas (nefelina sienitos e quartzo sienitos) dos maciços de Itatiaia, Passa Quatro e Morro Redondo, situados no limite entre Cretáceo e Terciário.

Estruturação Tectônica Ao contrário das características litológicas e metamórficas, que são diferenciadas para cada domínio (Figura 2), as feições estruturais se distribuem de forma homogênea, com exceção do Domínio Costeiro, onde as estruturas planares e lineares, bem menos desenvolvidas nos demais, denotam uma menor intensidade de deformação tectônica.

Todos os domínios litoestruturais apresentam foliações gnáissicas e miloníticas, de direção geral em torno de N40$50^{\circ} \mathrm{E}$, e mostram alternância entre faixas com mergulhos baixos e elevados $\left(30-80^{\circ}\right)$ para SE ou NW. Lineações de estiramento e minerais são materializadas por cristais ou agregados minerais de quartzo, feldspato, anfibólio, piroxênio, sillimanita e micas. Geralmente são direcionais a oblíquas, com caimentos inferiores a $20^{\circ}$ para NE ou SW. Ocorrem, ainda, dobras intrafoliais, isoclinais a fechadas e, subordinadamente, abertas, com planos axiais de baixo a alto ângulo de mergulho, sub-paralelos a oblíquos às zonas de cisalhamento.

A partir da relação de superposição (Tabela 1), as estruturas foram atribuídas a dois eventos tectônicos principais: um compressional (Dn-1) e outro direcional (Dn).

O evento tectônico Dn-1 é identificado por bandamento composicional ou xistosidade ( $\mathrm{Sn}-1)$, pouco freqüente nos gnaisses do Complexo Quirino e nos gnaisses granulíticos do Domínio Juiz de Fora. A foliação Sn-1 apresenta ângulo de mergulho inferior a $30^{\circ}$, por vezes está dobrada e contém uma lineação mineral e/ou estiramento (Ln-1) na direção do rumo de mergulho da foliação (down-dip). Estas estruturas são compatíveis com regime tectônico compressivo de direção NW-SE.

O evento tectônico Dn é registrado por uma foliação gnáissica ou por xistosidade $(\mathrm{Sn})$ e por foliação milonítica $(\mathrm{Sm})$, que apresentam alternância entre faixas com baixos e altos ângulos de mergulho (Figuras 1 e 2). Sn e Sm estão presentes em todos os domínios litoestruturais nos litótipos de idades Neo a Paleoproterozóicas. Associam-se lineações minerais e de estiramento ( $\mathrm{Ln}$ ), de caráter oblíquo a direcional, com caimentos inferiores a $20^{\circ}$ para NE ou SW. Ao longo das zonas de cisalhamento ocorre uma foliação milonítica (Sm) sub-horizontal a vertical e uma lineação de estiramento (Ln) NE-SW sub-horizontal e, raramente, sub-vertical. Estas estruturas são compatíveis com regime tectônico transcorrente a transpressivo dextral, relacionado à Orogênese Ribeira, causada por convergência crustal oblíqua de direção em torno de E-W.

A área em estudo é recortada por um expressivo feixe de zonas de cisalhamento transcorrentes anastomosadas, com direção em torno de NE-SW e dezenas de quilômetros de extensão 

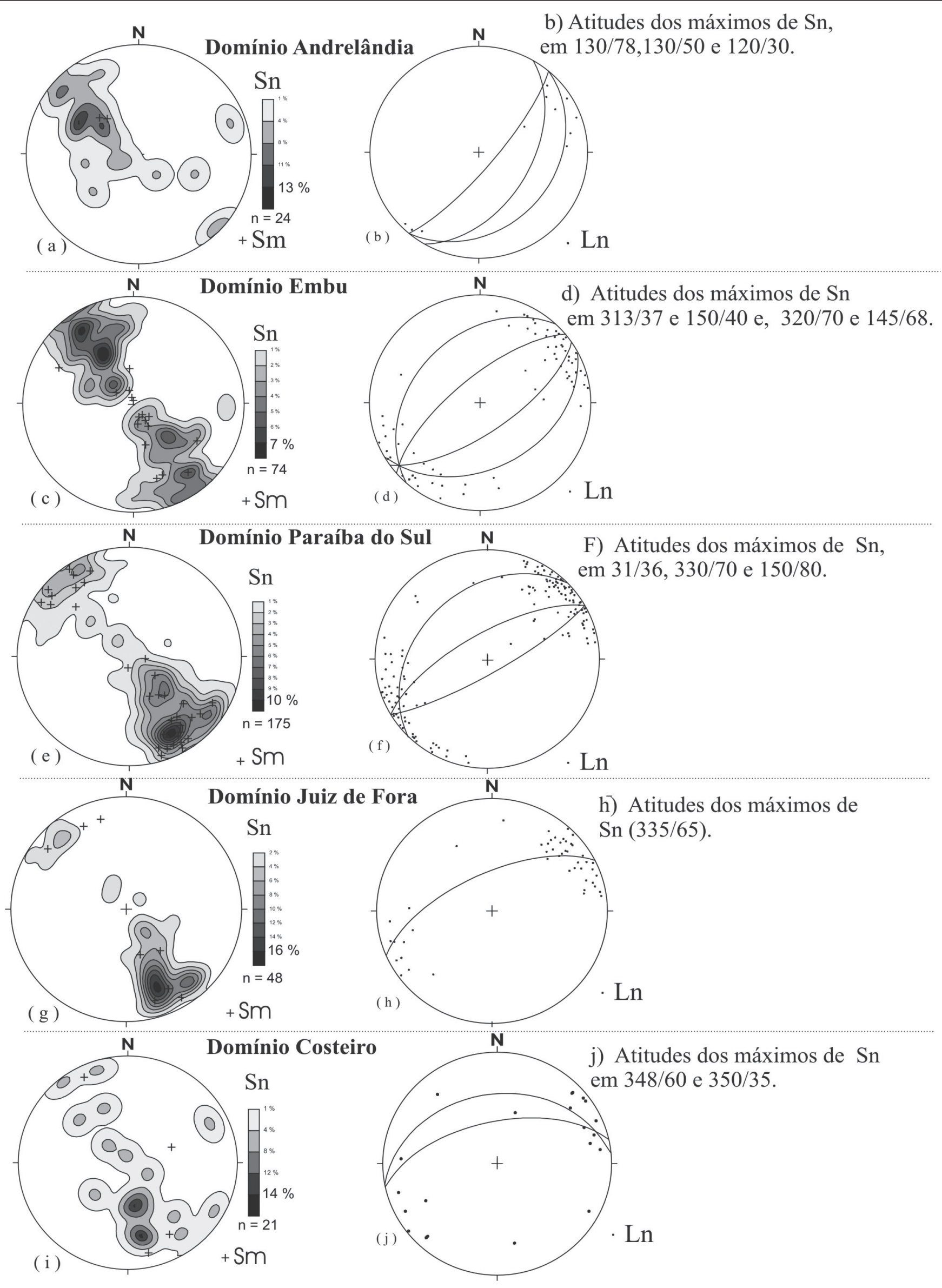

Figura 2 - Estereogramas polares: “ $a, c, e, g$, $i$ ” representam contornos dos pólos de Sn e os triângulos, pólos de Sm. Em “b, d, f, $h, j$," os pontos são estereogramas polares de Ln, contendo atitudes de Sn. 
(Figura 1), identificáveis no campo através de rochas miloníticas a ultramiloníticas. As zonas de cisalhamento (ZCs) mais expressivas, desenvolvidas ao longo dos limites dos domínios litoestruturais são: Rio Preto (ZCRP), Taxaquara (ZCT), Para- íba do Sul (ZCPS) e Arcádia Areal (ZCAA). A ZCPS possui direção NE-SW, altos mergulhos da foliação e lineações de estiramento direcionais. A ZCPS faz parte do sistema de zonas de cisalhamento Além Paraíba-Cubatão-Lancinha (Machado \&

Tabela 1 - Síntese das feições estruturais relativas à evolução estrutural Segmento Central do Cinturão Ribeira na região da Serra da Bocaina (Estados de São Paulo e Rio de Janeiro).

\begin{tabular}{|c|c|c|c|}
\hline Estruturas & Dn-1 & \multicolumn{2}{|c|}{ Dn } \\
\hline Foliação & $\begin{array}{l}\text { Sn-1 } \\
\text { - bandamento composional e xistosidade } \\
\Rightarrow \text { baixo ângulo de mergulho }(<358)\end{array}$ & $\begin{array}{l}\text { Sn } \\
\text { - foliação gnáissica, xistosidade e } \\
\text { foliação S-C } \\
\Rightarrow \text { baixos a altos ângulos de } \\
\text { mergulho }\end{array}$ & $\begin{array}{l}\text { Sm } \\
\text { - foliação milonítica } \\
\Rightarrow \text { baixos a altos ângulos de } \\
\text { mergulho }\end{array}$ \\
\hline Lineação & $\begin{array}{l}\text { Ln-1 } \\
\text { - lineação de estiramento down dip }\end{array}$ & \multicolumn{2}{|c|}{$\begin{array}{l}\text { Ln } \\
\text { - lineação de estiramento (mergulhos <208), oblíqua a direcional } \\
\text { - lineação subvertical }\end{array}$} \\
\hline Dobras & $\begin{array}{l}\text { - isoclinais a fechadas, ângulos interflancos } \\
\text { entre } 0^{\circ} \text { a } 608 \\
\text { - superfície axial e eixo subhorizontais } \\
\text { (recumbente a normal horizontal ) } \\
\text { - espessamento apical }\end{array}$ & \multicolumn{2}{|c|}{$\begin{array}{l}\text { - isoclinais a fechadas, ângulos interflancos entre } 08 \text { a } 608 \\
\text { - superfície axial subhorizontal à subvertical e eixos subhorizontais } \\
\text { (recumbente à normal horizontal) } \\
\text { - aberta a suave com eixo subvertical, ângulos interflancos }>1208 \\
\text { - espessamento apical }\end{array}$} \\
\hline $\begin{array}{l}\text { Feições } \\
\text { principais }\end{array}$ & $\begin{array}{l}\text { - estrutura tangencial e lineação down-dip } \\
\text { - dobras em bainha } \\
\text { - foliação subhorizontall } \\
\text { - assimetria de dobras com vergência } \\
\text { predominante para NW }\end{array}$ & \multicolumn{2}{|c|}{$\begin{array}{l}\text { - estrutura tangencial com lineação rotacionada (direcional a } \\
\text { oblíqua) } \\
\text { - estruturas direcionais (médio a alto ângulos de mergulhos e } \\
\text { lineação direcional a obliqua) } \\
\text { - predomínio de dobras simétricas e quando assimétricas vergência } \\
\text { para NE } \\
\text {-foliação sub-horizontal a subvertical } \\
\text { - coexistência de duas foliações (baixos e altos ângulos de } \\
\text { mergulho) } \\
\text { - inflexão da foliação Sn } \\
\text { - grandes zonas de cisalhamento dúcteis }\end{array}$} \\
\hline Tectônica & Cavalgamento para NW & \multicolumn{2}{|c|}{ Transpressão dextral } \\
\hline
\end{tabular}

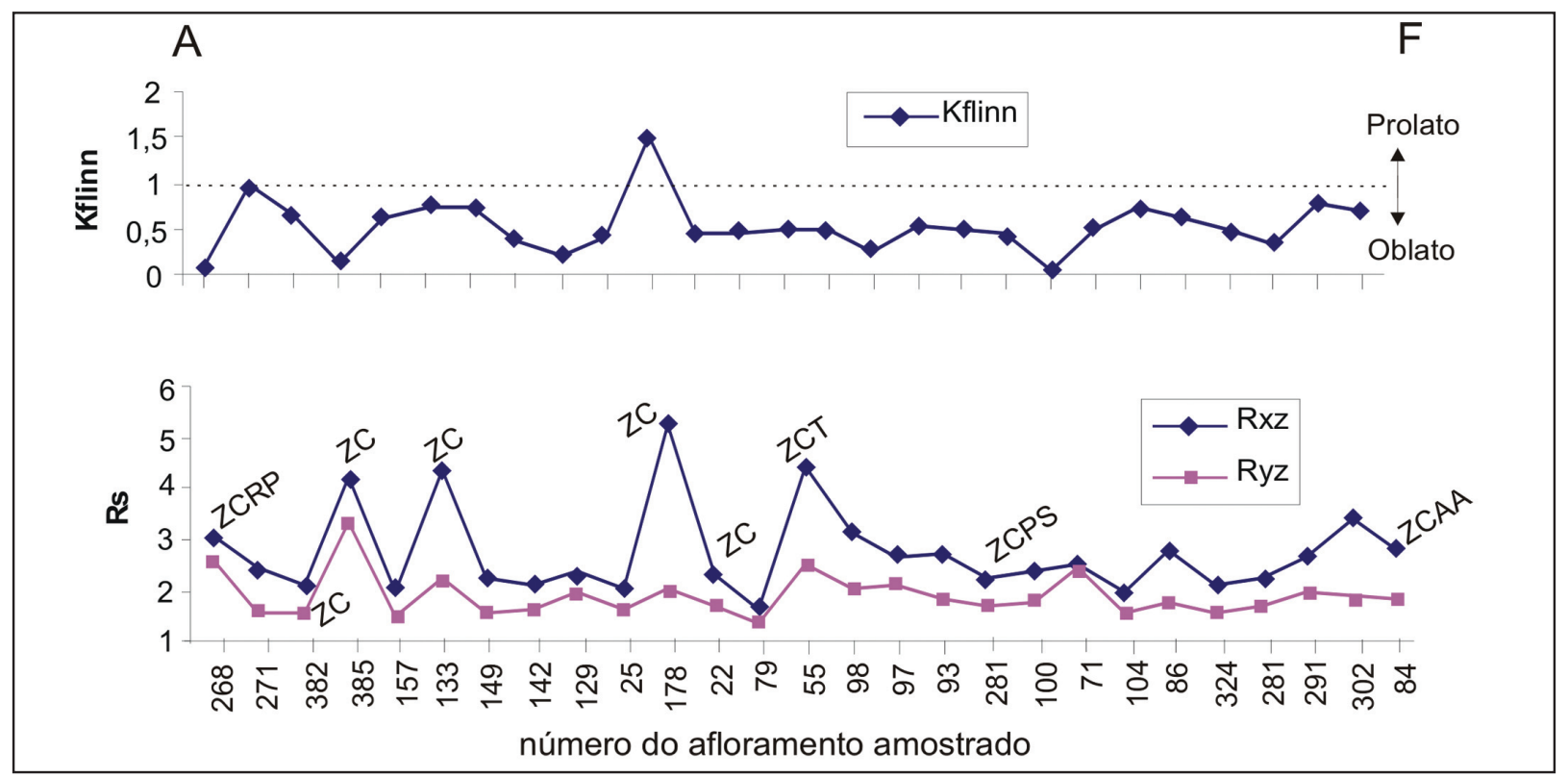

Figura 3 - Os gráficos mostram a variação dos parâmetros Rxz, Ryz e Kflin do perfil A-F (composição dos perfis AB-CD-EF). ZC representa zonas de cisalhamento. ZCRP (Z.C. Rio Preto), ZCT (Z.C. Taxaquara), ZCPS (Z.C. Paraíba do Sul) e ZCAA (Z.C. Arcádia Areal). 
Endo 1994). Seu prolongamento para NE corresponde à Zona de Cisalhamento de Além Paraíba ou Paraíba do Sul (Campanha 1981). A ZCRP possui direção $\mathrm{N} 65^{\circ} \mathrm{E}$ com mergulhos baixos a médios $\left(30^{\circ}-55^{\circ}\right)$ para SE. Localmente, observa-se foliação gnáissica com lineação tipo down dip. Outra importante zona de cisalhamento é a Taxaquara (ZCT) descrita por Hasui et al. (1978), que no seu ramo sudoeste sofre uma deflexão restritiva (restraining bend), migrando da direção geral $\mathrm{N}^{\circ} 5^{\circ} \mathrm{E}$ para $\mathrm{N} 30^{\circ} \mathrm{E}$ (Figura 1). O prolongamento da ZCT configura um duplex compressivo constituído por uma rede anastomosada de zonas de cisalhamento secundárias. Próximo ao litoral, ocorre a Zona de Cisalhamento Arcádia Areal (ZCAA), conforme Al-

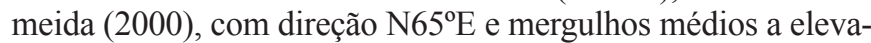
dos para NW e localmente para SE. A lineação de estiramento é sub-horizontal e direcional. A ZCAA corresponde ao Limite Tectônico Central (CTB) (Almeida et al. 1998) que delimita os terrenos Oriental e Ocidental (Heilbron et al. 2000 e Trouw et al. 2000). A espessura da Zona de Cisalhamento Paraíba do Sul pode chegar a $6 \mathrm{~km}$, enquanto que as demais zonas de cisalhamento atingem no máximo $3 \mathrm{~km}$.

O caráter direcional das lineações ao longo dessas zonas de cisalhamento, associado a indicadores cinemáticos de escala micro-, mesoscópica (porfiroclastos rotacionados e foliação $\mathrm{S}-\mathrm{C}$ ) a regional, indica rejeitos transcorrentes predominantes dextrais. O desenvolvimento das zonas de cisalhamento ocorreu em condições de temperaturas de fácies anfibolito médio a alto. A Zona de Cisalhamento Rio Preto (ZCRP) contém paragêneses metamórficas de grau mais elevado (anfibolito alto) e exibe maior intensidade ou magnitude de deformação. Os grãos de feldspatos encontram-se recristalizados e muito estirados, com feições típicas de temperaturas superiores à $600^{\circ} \mathrm{C}$.

ANÁliSE DE DEFORMAÇÃo PELO MÉTODO Rf/ $\phi$ Para a melhor compreensão dos mecanismos deformacionais responsáveis pela estruturação interna do Segmento Central do Cinturão Ribeira, que expõe níveis crustais profundos, foram realizadas análises de deformação em 29 amostras de gnaisses. As amostras de rochas coletadas ao longo de todos os domínios litoestruturais (Figura 1), apresentam foliações gnáissica (Sn) e milonítica (Sm), que registram as deformações promovidas pela Orogênese Ribeira.

Procedimentos A deformação finita foi estimada através da forma e orientação dos grãos de quartzo e feldspato, considerados como marcadores isovolumétricos e utilizando-se o método de Rf/ $\phi$ (Ramsay 1967, Lislie, 1985). Esta técnica geométrica permite distinguir a elipsidade inicial $\mathrm{R}_{\mathrm{i}}$ (primária) da elipsidade deformacional $\mathrm{R}_{\mathrm{s}}$ através da relação obtida a partir da elipsidade $\mathrm{R}_{\mathrm{f}} \mathrm{O}$ método $\mathrm{Rf} / \phi$ tem sido amplamente utilizado para análise de deformações regionais, pois oferece uma boa correlação entre as razões de deformação obtidas em escala de amostra e a estruturação regional em estudo (Jain \& Anand 1988). A relação entre os eixos maiores e menores da partícula deformada representa o valor de $\mathrm{R}_{\mathrm{f}}$ e o valor $\phi$ o ângulo entre a direção de máximo estiramento e o traço da foliação (Ramsay \& Huber 1983, Fiori 1997). Os procedimentos adotados neste trabalho foram:

1) coleta de amostras orientadas no campo;

2) corte das amostras ao longo de dois planos perpendiculares à foliação, sendo o plano cinemático XZ paralelo à lineação de estiramento e o YZ ortogonal a ela;

3) confecção de seções delgadas paralelas aos planos cinemáticos XZ e YZ;

4) captura de imagens no formato *.jpg, com resolução de 800 x 600 pixels, das seções delgadas, através da câmera digital
JVC-TKC1380 acoplada a um sistema de microscópio e lupa Leica DM-RX com luz polarizada e objetiva de 2,5 x;

5) processamento das imagens raster com o programa Corel Photo-paint 9.0, em termos de contraste, nitidez e saturação, visando realçar o contorno dos grãos deformados;

6) importação das imagens para o programa AutoCad e digitalização, com o comando pline, das extremidades dos eixos maior e menor de cada marcador (ao redor de 70 a 120 cristais/ lâmina), cujas coordenadas foram exportadas através de uma rotina em autolisp;

7) cálculo dos parâmetros de $\mathrm{Rf} / \phi$ e a razão de deformação $\mathrm{R}_{\mathrm{S}}$ com o programa Instrain 3.02 (Erslev 1993). Nas análises, grãos de quartzo e feldspatos foram estudados em conjunto.

A partir dos resultados bidimensionais $\mathrm{Rs}_{\mathrm{xz}}$ e $\mathrm{Rs}_{\mathrm{yz}}$, considerando-se as médias harmônicas, foram calculados os parâmetros tridimensionais $\mathrm{K}_{\text {Flinn }}$ (Ramsay \& Huber 1983), de Lode (v) e Nadai $\left(\bar{\varepsilon}_{\mathrm{s}}\right)$ descritos por Hossack (1968) e Hsu (1966), descritos na Tabela 2.

(v) $v_{\text {Lode's }}=\left(\ln +\ln \mathrm{R}_{\mathrm{yz}-} \ln -\ln \mathrm{R}_{\mathrm{xy}}\right) /\left(\ln +\ln \mathrm{R}_{\mathrm{yz}-} \ln +\ln \mathrm{R}_{\mathrm{xy}}\right)$

$\left(\bar{\varepsilon}_{s}\right) \varepsilon_{\mathrm{s}}=$

$$
\left(\ln \mathrm{R}_{\mathrm{xy}}{ }^{2}+\ln \mathrm{R}_{\mathrm{yz}}{ }^{2}+\ln \mathrm{R}_{\mathrm{xz}}{ }^{2}\right)^{1 / 2}
$$

A forma do elipsóide de deformação finita é determinada da seguinte maneira:

- $\mathrm{K}_{\text {Flinn }}<1$ e $v>0$ correspondem ao campo do achatamento ou dos elipsóides oblatos;

- $\mathrm{K}_{\text {Flinn }}>1$ ou $v<0$ indicam constricção ou deformação prolata.

- $\mathrm{K}_{\text {Flinn }}=1$ ou $v=0$, a deformação é plana. O parâmetro de Nadai $\left(\bar{\varepsilon}_{s}\right)$ indica a intensidade de deformação tridimensional.

Resultados da Análise de Deformação Os resultados da análise de deformação sumarizados a partir dos dados da mostram as seguintes variações:

\section{Rochas com foliação Sn:}

$-\mathrm{K}_{\text {Flinn }}$ variando de 0,1 a 0,99 e $\mathrm{K}_{\text {Flinn }}$ médio $=0,53$

$-\mathrm{R}_{\mathrm{xz}}$ entre 1,6 e 5,2 e $\mathrm{R}_{\mathrm{xz}}$ médio $=2,73 ; \mathrm{R}_{\mathrm{yz}}$, entre $1,4 \mathrm{e}$

2,6, e valor médio de 1,83

-Intensidades de deformação $\left(\overline{\mathcal{E}}_{\mathrm{s}}\right)$ entre 0,35 e 1,05 , valor médio de 0,66

\section{Rochas com foliação Sm:}

$-\mathrm{K}_{\text {Flinn }}$ entre 0,02 e 0,75 , e $\mathrm{K}_{\text {Flinn }}$ médio $=0,40$

$-\mathrm{R}_{\mathrm{xz}}$ entre 2,0 e 4,42 e $\mathrm{R}_{\mathrm{xz}}$ médio $=2,77 ; \mathrm{R}_{\mathrm{yz}}$ entre $1,56 \mathrm{e}$ 3,32 , e média de 2,1

-Intensidades de deformação $\left(\mathcal{E}_{\mathrm{s}}\right)$ entre 0,52 e 1,09 , e valor médio de 0,72

\section{Domínios litoestruturais:}

-DJF: $\mathrm{R}_{\mathrm{xz}}$ entre 2,20 a 3,38 e $\mathrm{R}_{\mathrm{yz}}$, entre 1,55 a 2,61. $\mathrm{K}_{\text {Flinn }}$ entre 0,03 a 0,78 (achatamento) -DPS: $\mathrm{R}_{\mathrm{xz}}$ entre 1,63 a 5,22 e $\mathrm{R}_{\mathrm{yz}}$, entre 1,39 a 2,55. $\mathrm{K}_{\text {Flinn }}$ entre 0,21 a 1,53 (achatamento/ constricção)

-DE $\mathrm{R}_{\mathrm{xz}}$ entre 1,96 a 4,38 e $\mathrm{R}_{\mathrm{yz}}$, entre 1,49 a $3,32 . \mathrm{K}_{\text {Flinn }}$ entre 0,12 a 0,99 (achatamento)

Zonas de cisalhamento (ZCs): Os perfis AB-CD-EF (Figura 3) apresentam a variação dos parâmetros Rs (razão de deformação) e $\mathrm{K}_{\text {Flinn }}$, ao longo das principais zonas de 
cisalhamento.

-As zonas de cisalhamento apresentam $\mathrm{R}_{\mathrm{xz}}$ maior que 3; $\mathrm{K}_{\text {Flinn }}$ entre 0,45 e 0,75 (tectonitos SL)

-Zona de cisalhamento secundária - ponto $178-\mathrm{K}_{\text {Flinn }}$ $=1,53$ (tectonito LS)

-Zona de Cisalhamento Rio Preto - $\mathrm{K}_{\text {Flinn }}=0,11$ (tectonito $\mathrm{S}$ )

\section{REGIME DE DEFORMAÇ̃̃O REGIONAL}

Elipsóide de Deformação Os elipsóides de deformação apresentam formas geralmente oblatas, correspondentes ao campo do achatamento (Tabela 2). No diagrama de Flinn (Figura 4), a maioria dos valores de $\mathrm{K}_{\text {Flinn }}$ concentra-se na porção intermediária do gráfico, entre 1,5 a 2.0 na abscissa $\mathrm{R}_{\mathrm{yz}}$ e, 1,25 a 1,5 na ordenada $\mathrm{R}_{\mathrm{yz}}$. Na análise total, ou mesmo por domínios litoestruturais (Figura 4), verificou-se a tendência de aumento dos valores de $\mathrm{K}_{\text {Flinn }}$ na direção paralela ao eixo da deformação plana, e menos pronunciada na direção paralela à abscissa $\mathrm{R}_{\mathrm{yz}}$, rumo à $\mathrm{K}<1$, predominando tectonitos tipo SL e raramente tectonitos tipo S. A maioria das zonas de cisalhamento apresenta razões de deformação mais elevadas, sendo $\mathrm{R}_{\mathrm{xz}}$ maior que 3 .

Em relação às foliações $\mathrm{Sn}$ e $\mathrm{Sm}$, a forma do elipsóide de deformação finita é semelhante (oblata), e os valores de razão de deformação (Rs), nos planos XZ e YZ, não apresentaram grandes contrastes, exceto uma única amostra no domínio Paraíba do Sul (ponto 178, Tabela 2), cujo elipsóide é prolato. As foliações $\mathrm{Sn}$ e Sm foram consideradas síncronas e teriam se desenvolvidos através de zonas de cisalhamento dúcteis, de forma semelhante às superfícies $\mathrm{S}$ e $\mathrm{C}$ (Berthé et al. 1979). A superfície S é próxima ao plano XY de deformação principal, e a lineação de estira- mento, dentro dela, é aproximadamente paralela a X, direção do eixo maior do elipsóide de deformação finita. A superfície $\mathrm{C}$ é paralela à zona de cisalhamento principal, e o ângulo entre $\mathrm{S}$ e C (ângulo Y') diminui com o aumento da deformação.

$\mathrm{O}$ diagrama de Hsu (Figura 5a) mostra o posicionamento dos valores de intensidade da deformação $\left(\bar{\varepsilon}_{\mathrm{s}}\right)$ e a forma dos elipsóides ( $v$ ) (Hsu 1966). A partir da concentração média dos parâmetros obtidos no diagrama, inferiu-se: estiramento entre

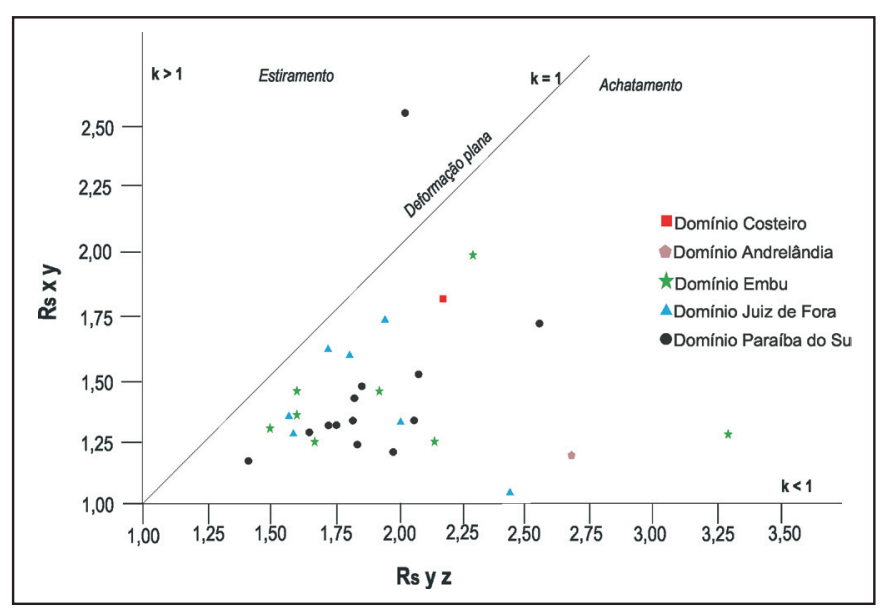

Figura 4-Diagrama de Flinn com dados de Rs discriminados por domínio litoestrutural no Segmento Central do Cinturão Ribeira.

Tabela 2 - Resultados das análises de deformação nos domínios litoestruturais do Cinturão Ribeira (DA, DE, DPS, DJF e DC).

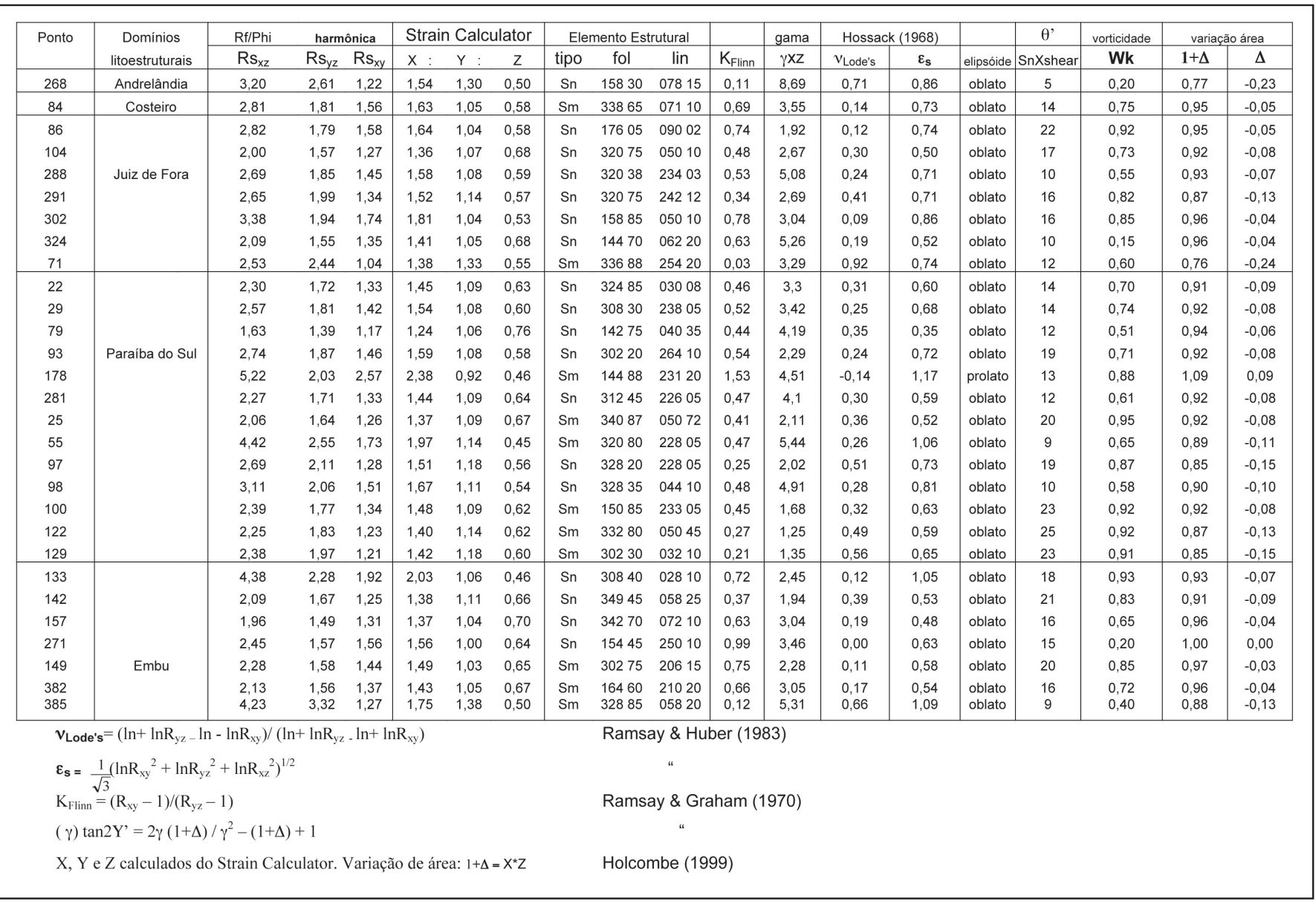




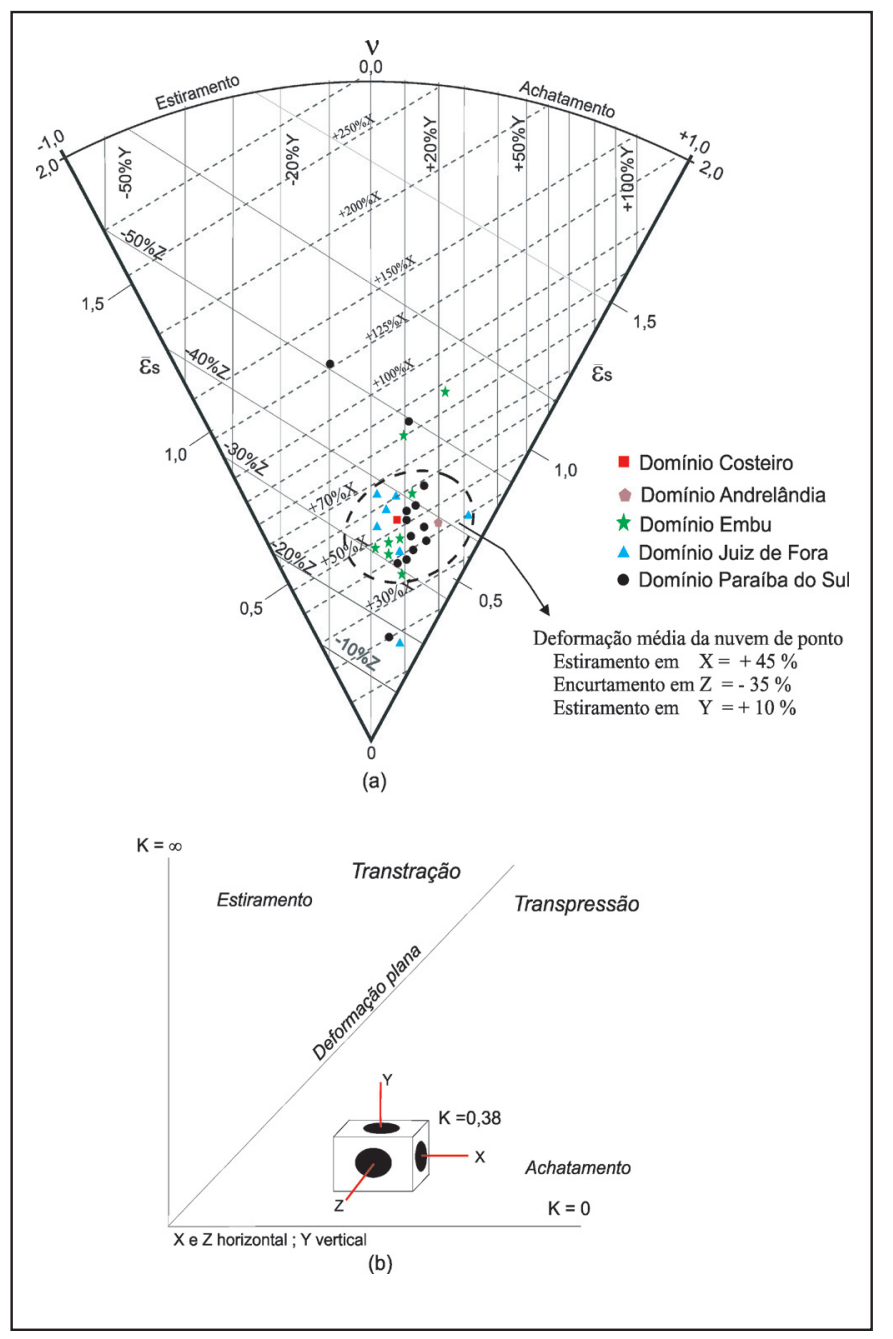

Figura 5 - (a) Diagrama de Hsu dos parâmetros de Lodes e Nadai (b) Representação esquemática do elipsóide geral de deformação para o Segmento Central do Cinturão Ribeira.

30 a $70 \%$ ao longo do eixo $\mathrm{X}$ (média de $+45 \%$ em X), encurtamento entre 30 a $40 \%$ ao longo do eixo $Z$, (média de $-35 \%$ em $\mathrm{Z}$ ), estiramento entre 0 e $20 \%$ ao longo do eixo Y (média de $+10 \%$ em Y).

A partir dos valores médios de estiramento e encurtamentos ao longo dos eixos principais de deformação, inferiu-se um elipsóide médio de deformação (Figura $5 \mathrm{~b}$ ) para toda a área de estudo. Considerando-se estiramento de $45 \%$ em X (direção NE-SW), estiramento de $10 \%$ em Y (vertical) e encurtamento em 35\% (NW-SE), o elipsóide de deformação finita apresenta forma oblata e $\mathrm{K}_{\text {Flinn }}$ igual a 0,38 , situando-se no campo do achatamento. Análises de deformação realizadas por Dayan \& Keller (1990) na Zona de Cisalhamento Paraíba do Sul, nas vizinhanças de Três Rios (RJ), também resultaram em elipsóides oblatos, compatível com o regime transpressivo deste segmento do Cinturão Ribeira.

Estimativas do Rejeito Transcorrente As rochas afetadas por zonas de cisalhamento dúcteis, durante processos orogênicos, guardam relação entre distorção, rotação e deslocamento. Ramsay e Graham (1970) estabeleceram formulações matemáticas para determinar a deformação cisalhante gama $(\gamma)$ ao longo de zonas de cisalhamento e, com isso, quantificaram os deslocamentos associados. A deformação cisalhante gama $(\gamma)$ pode ser obtida pela expressão:

$$
\tan 2 Y^{\prime}=2 \gamma(1+\Delta) / \gamma^{2}-(1+\Delta)+1
$$

Onde Y'é a orientação do eixo maior do elipsóide de deformação finita em relação ao traço de uma zona de cisalhamento (medida através da obliqüidade entre o traço de $\mathrm{Sn}$ e as zonas de cisalhamento em mapa); $\gamma$ é a deformação cisalhante e $1+\Delta$ é variação de área $\left(1+\Delta=X^{*} Z\right)$, em escala de amostra, calculada a partir de eixos cinemáticos $\mathrm{X}$ e $\mathrm{Z}$, inferidos das razões $\mathrm{Rs}_{\mathrm{xz}}$, $\mathrm{Rs}_{\mathrm{yz}}$ e $\mathrm{Rs}_{\mathrm{xy}}$ (Tabela 2) através do programa Strain Calculator (Holcombe 1999).

A partir da integração de $\gamma$ em relação à largura de uma zona de cisalhamento pode-se estimar o deslocamento (D) de uma zona de cisalhamento (Ramsay \& Graham 1970), onde D é equivalente à área sob a curva de variação de $\gamma$ versus a largura do cisalhamento $(\Delta \mathrm{x})$.

$$
D=\int_{0}^{x} \tilde{\mathrm{a}} \Delta \mathrm{x}
$$

O parâmetro $\gamma$ é a deformação cisalhante e $\Delta \mathrm{x}$ a largura da zona de deformação, considerando-se zonas de cisalhamento simples.

Através dos perfis A-B,C-D e E-F (Figura 1) estimou-se o deslocamento mínimo do Segmento Central do Cinturão Ribeira, na faixa entre as zonas de Cisalhamento Rio Preto (ZCRP) e Arcádia Areal. Somados, os perfis têm $65 \mathrm{~km}$ de extensão e mostram a variação total da deformação cisalhante $(\gamma)$ na área afetada pela orogênese Neoproterozóica (Figura 6). Os valores de $\gamma$ (Tabela 2) foram obtidos da variação de área no plano horizontal. O cálculo de área abaixo das curvas indicadas na Figura 6 possibilitou a estimativa de um rejeito dúctil de $204 \mathrm{~km}$ para esta porção do segmento do Cinturão Ribeira. Em comparação às outras áreas do cinturão, Fiori (1997) estimou através da integração de $\gamma$, para as falhas de Lancinha e Morro Agudo, ao norte de Curitiba (PR), deslocamentos totais da ordem, respectivamente, de 100-142 km e de $87-122 \mathrm{~km}$.

Almeida \& Ebert (2001) estimaram o encurtamento total mínimo por cavalgamento a partir da reconstituição de modelos gravimétricos, na mesma região em estudo, considerando a translação dos blocos ao longo das zonas de cisalhamento Rio Preto e Paraíba do Sul e de duplexes de crosta inferior. O balanceamento de seção mostrou que os $80 \mathrm{~km}$ de extensão (perfil G-G') eram originalmente no mínimo $125 \mathrm{~km}$, o que equivale ao encurtamento mínimo de $36 \%$, semelhante ao encurtamento (-35\%) inferido do elipsóide médio de deformação (Figura 5a). A restauração deste perfil requer um transporte frontal NW-SE mínimo de $65 \mathrm{~km}$ ao longo das zonas de cisalhamento. O rejeito direcional NE-SW estimado através da integração da deformação cisalhante $(\gamma)$ através do perfil de $80 \mathrm{~km}$, simultâneo durante a convergência oblíqua, resultou em $204 \mathrm{~km}$.

Índice de Vorticidade $\mathrm{O}$ índice de vorticidade $(\mathrm{Wk})$, que representa o grau de coaxilidade da deformação, foi estimado neste trabalho através da relação entre a elipsidade $R_{x z}$ e $Y^{\prime}$, medida a partir da obliqüidade entre o traço da foliação (Sn) e as zonas de cisalhamento (ZCs) em mapa. O diagrama da Figura 7, modificado de Tikoff \& Fossen 1993, mostra a relação entre a elipsidade $\mathrm{R}_{\mathrm{xz}}$ e $\mathrm{Y}^{\prime}$, onde $\mathrm{R}_{\mathrm{xz}}$ representa a razão de deformação (no plano $\mathrm{XZ}$ ) e Y', a orientação do eixo maior do elipsóide de deformação finita, relacionado na Equação 3. A partir desta relação, obtém-se o índice de vorticidade Wk para o Segmento Central do Cinturão Ribeira.

$\mathrm{O}$ cisalhamento é puro quando $\mathrm{Wk}=0$, simples quando $\mathrm{Wk}$ $=1$ e geral para valores intermediários $(0<\mathrm{Wk}<1)$, caso em 


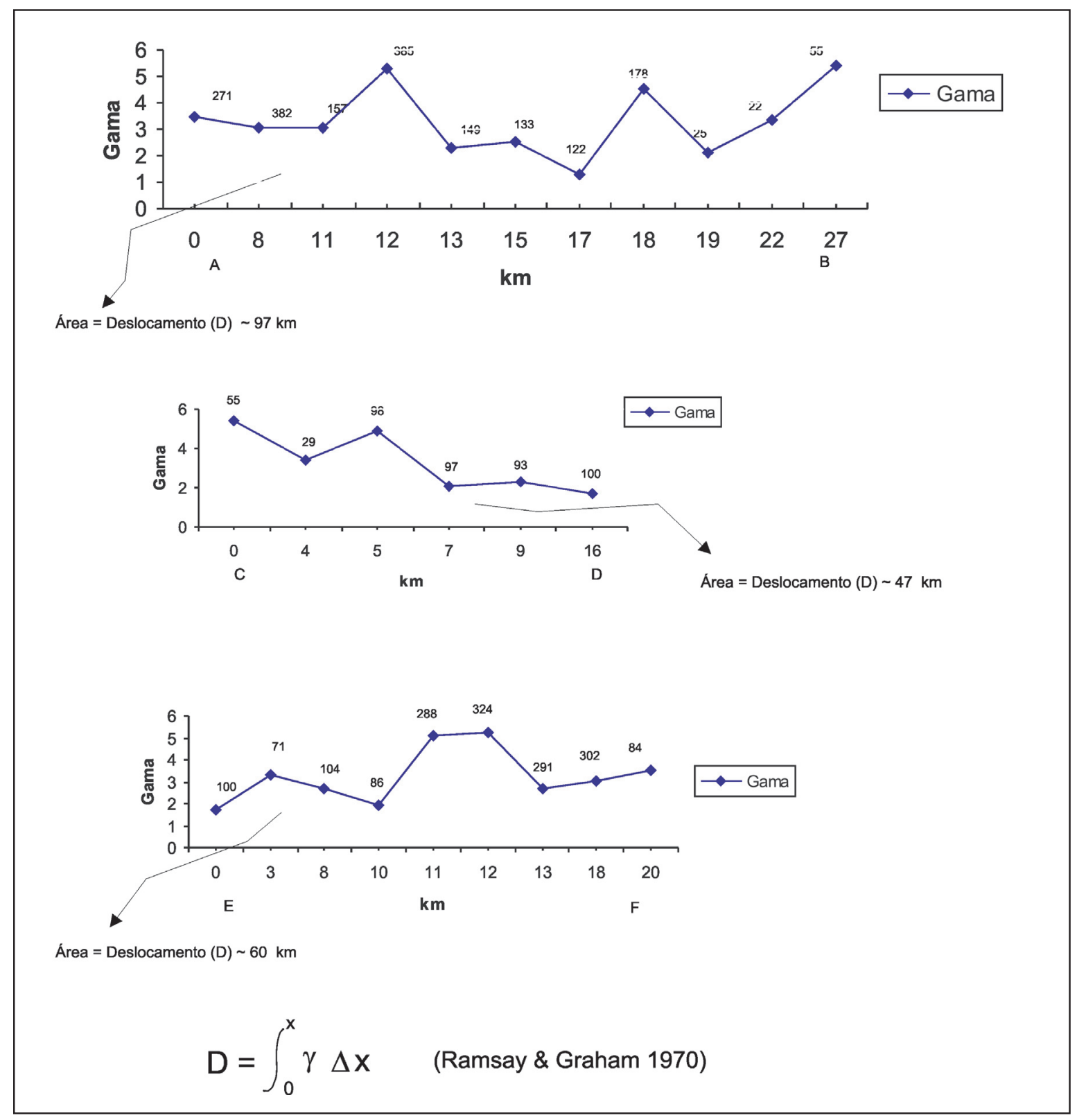

Figura 6 - Perfis A-B, C-D e E-F mostram a variação de $\gamma$ x distância $(\mathrm{km})$ perpendicular a uma faixa do segmento central do Cinturão Ribeira (Figura 1). A integração de $\gamma$ permite estimar o valor do deslocamento total (D) deste cinturão, na área. O deslocamento total mínimo foi $204 \mathrm{~km}$, estimado a partir da soma dos deslocamentos calculados nos três perfis $(\mathrm{AB}=97 \mathrm{~km} ; \mathrm{CD}=47 \mathrm{~km}$ e EF $=60 \mathrm{~km})$.

que se considera cisalhamento simples agindo simultaneamente a cisalhamento puro (Hanmer \& Paschier 1991). Fossen et al. (1994) e Tikoff \& Fossen (1995) sugerem um modelo de transpressão em que valores de $\mathrm{Wk}>0,81$ implicam em transpressão com predomínio de cisalhamento transcorrente e $\mathrm{Wk}<0,81$, em transpressão dominada por cisalhamento puro.

$\mathrm{O}$ índice de vorticidade Wk, na área em estudo (Figura 7), variou entre 0,15 e 0,95 (Wk médio 0,68). No geral, a maioria dos valores de Wk é menor que 0,81. Nos domínios Embu e Juiz de Fora predomina transpressão dominada por cisalhamento puro, onde Wk $<0,81$ (Figuras 7 e 8). No Domínio Paraíba do Sul, à noroeste da Zona de Cisalhamento Taxaquara (ZCT) ocorre transpressão com predomínio de transcorrência (Wk > $0,81)$ e, à sudeste da ZCT, a transpressão é também dominada por cisalhamento puro (Figuras 7 e 8). Ao longo de todo o Cinturão Ribeira, os valores de vorticidade (Wk), segundo Ebert $\&$ Hasui (1998), variam entre 0,25 e 0,75 , que corresponde aos valores encontrados no presente estudo. Aqui, encontram-se feições estruturais características de dois tipos de deformação: transcorrência (deformação não coaxial - estruturas direcionais de movimentação dextral) e encurtamento perpendicular à zona de cisalhamento (deformação coaxial - dobras simétricas). A combinação dos dois tipos de deformação corresponde à transpressão (Sanderson \& Marchini 1984).

Transpressão Dextral Regionalmente, todo o Cinturão Ribeira sofreu transpressão dextral gerada pela colisão oblíqua entre paleocontinentes na direção E-W, ocorrendo a partição da deformação, com a conjunção de estruturas contracionais NWSE e estruturas transcorrentes NE-SW, ao longo desse cinturão. $\mathrm{Na}$ área, encontram-se feições estruturais características de dois tipos de deformação: transcorrência (deformação não coaxial estruturas direcionais de movimentação dextral) e encurtamento perpendicular à zona de cisalhamento (deformação coaxial - dobras simétricas) que, em conjunto resultou em transpressão, e foram explicados como partição da deformação regional, devi- 


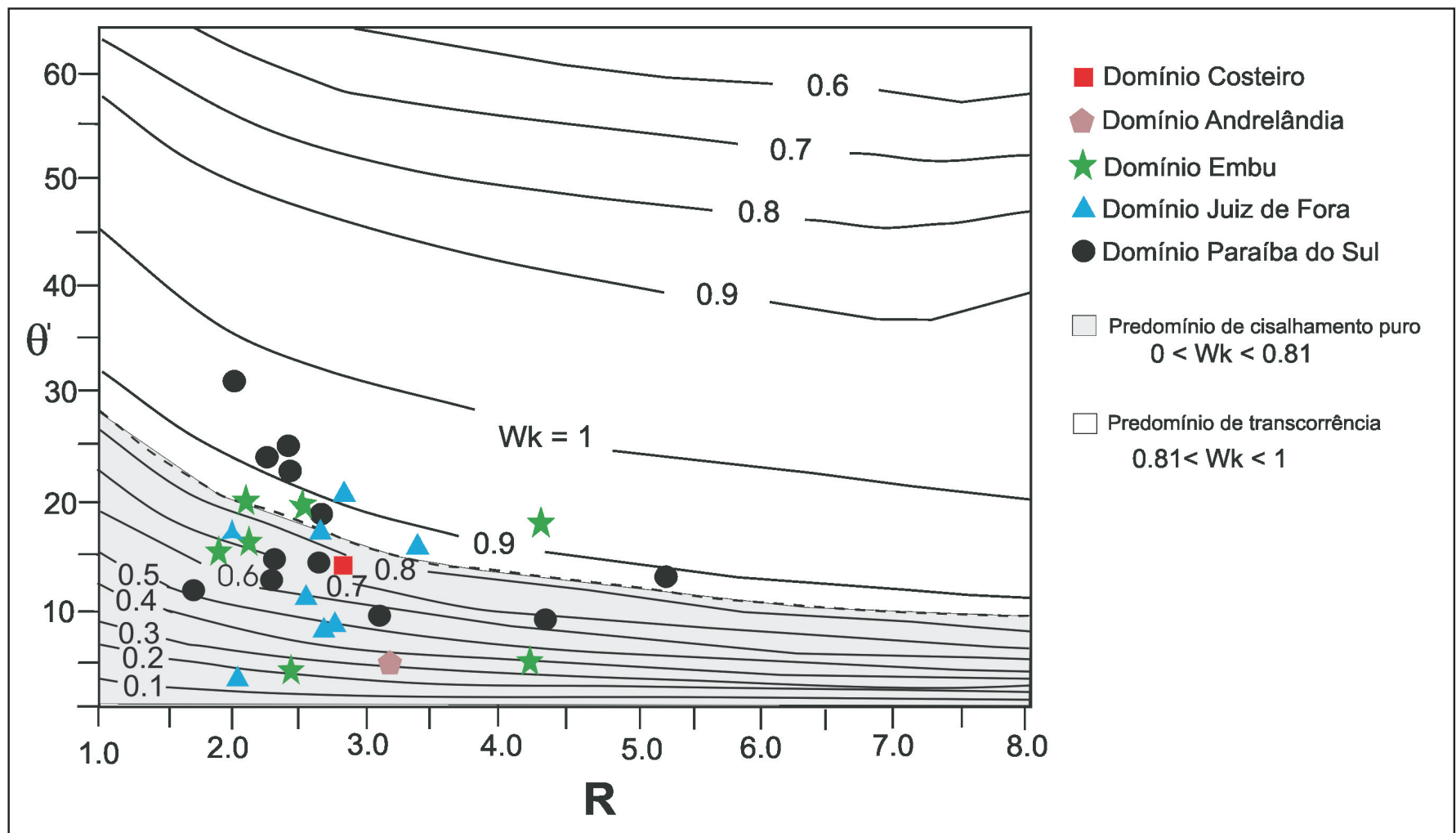

Figura 7 - Diagrama de classificação do índice de vorticidade (Wk), apresentando a relação entre $R$ (razão de deformação) e Y' (ângulo entre o eixo X da elipse de deformação e a zona de cisalhamento, para os diferentes domínios litoestruturais. Modificado de Tikoff \& Fossen (1995).

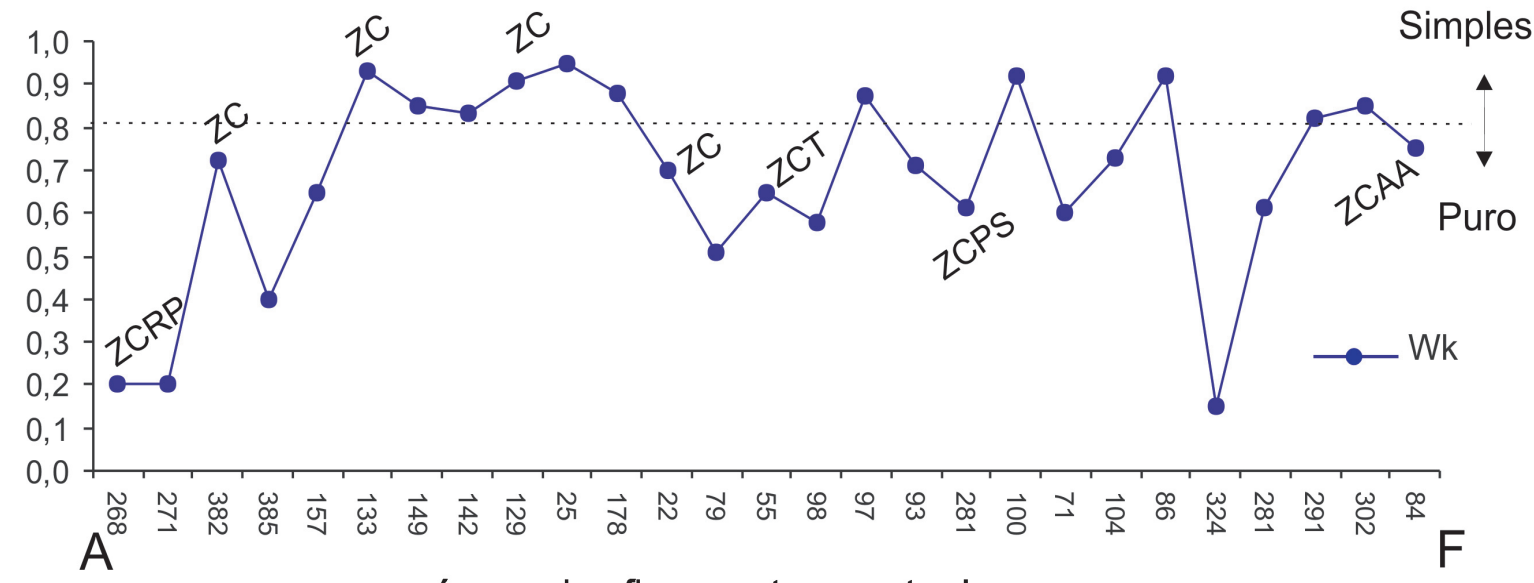

número do afloramento amostrado

Figura 8 - O gráfico mostra a variação do índice de vorticidade (Wk) ao longo do Cinturão Ribeira (perfil A-F da Figura 1). A linha tracejada na ordenada $\mathrm{Wk}=0,81$ separam os domínios com regime de transpressão dominada por cisalhamento puro $(\mathrm{Wk}<0,81) \mathrm{e}$ o de transpressão dominada por cisalhamento simples $(\mathrm{Wk}>0,81)$.

do à convergência E-W que resultou no Cinturão Transpressivo Rio Paraíba do Sul - CTRPS (Ebert \& Hasui 1998).

Como produto da transpressão, ocorreu espessamento crustal com o desenvolvimento de estruturas em flor positiva e do tipo restraining bend (duplex compressivos) nas inflexões de grandes zonas de cisalhamento (Taxaquara-Valença), onde predomina $\mathrm{Wk}<0,81$ (dominada por cisalhamento puro).
A maioria dos elipsóides apresenta uma orientação dos eixos maiores $(\mathrm{X})$ ao redor de NE-SW sub-horizontal, dos eixos menores $(Z)$ com baixos a médios mergulhos segundo a direção NW ou SE e o intermediário (Y) com extensão sub-vertical (Figura 9). Esta orientação é compatível com um regime tectônico transcorrente. Alguns elipsóides apresentam eixos X com direções NW-SE e NNE-SSW, compatíveis com zonas de cavalga- 


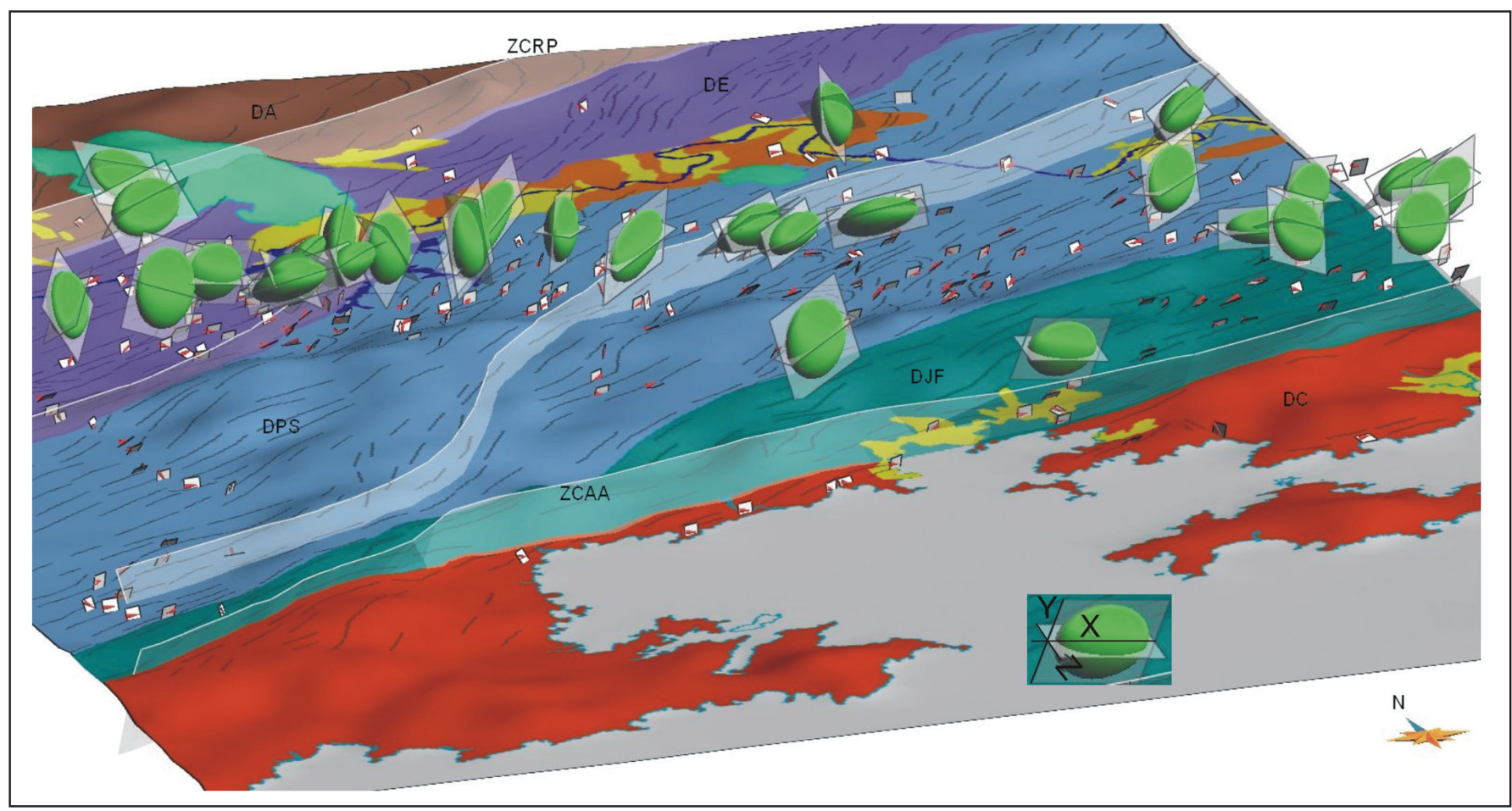

Figura 9 - Visão perspectiva de distribuição, forma e orientação dos elipsóides de deformação finita nos principais domínios litoestruturais: DA (Andrelândia), DE (Embu), DPS (Paraíba do Sul), DJF (Juiz de Fora) e DC (Costeiro); entre as zonas de cisalhamento: ZCRP (Rio Preto) e ZCAA (Arcádia Areal). Os elipsóides estão formando pelos os planos XY e XZ, representados nos eixos X, Y e Z. As placas menores representam a distribuídas da foliação ao longo das linhas de forma (traços da foliação).

mento frontais a oblíquas.

O regime transpressivo propiciou também, segundo Machado et al. (2000) e Nummer (2001), o desenvolvimento de sítios extensionais, em algumas zonas de cisalhamento na região, que favoreceram a ascensão e colocação de magmas graníticos. A amostra do ponto 178, a sul da Represa do Funil, foi o único exemplo de tectonito do tipo prolato analisado (Tabela 2), com deformação no campo do estiramento. A proximidade do ponto 178, em relação a zonas de cisalhamento e ao corpo granítico nas imediações da Represa do Funil podem estar correlacionados à existência desses sítios extensionais.

As principais feições estruturais relacionadas ao regime transpressivo na área envolvem:

a) tectonitos predominantes SL (oblatos);

b) foliações sub-horizontal a vertical, sub-paralelas às principais zonas de cisalhamento;

c) lineações de estiramento sub-horizontais, direcional a oblíqua em relação às foliações sub-horizontal a vertical;

d) eixos de dobras formando pequeno ângulo com as zonas de cisalhamento. Para a acomodação das estruturas geradas neste regime, ocorreu a partição da deformação com a combinação de estruturas coaxiais NW-SE e de cisalhamento simples NE-SW.

CONCLUSÕES Os elipsóides de deformação finita determinados para a região da Serra da Bocaina são geralmente oblatos (campo do achatamento). Em relação às foliações $\mathrm{Sn}$ e $\mathrm{Sm}$, a razão de deformação (Rs) nos planos XZ e YZ não apresentam grandes contrastes, o que é característico de elipsóides oblatos. Apenas uma amostra do domínio Paraíba do Sul revelou elip- sóide prolato $\left(\mathrm{K}_{\mathrm{Flinn}}=1,53\right)$. Os resultados plotados no diagrama de Hsu mostram os seguintes intervalos: estiramento entre 30 a $70 \%$ ao longo do eixo X; encurtamento entre 30 a $40 \%$ ao longo do eixo Z; estiramento entre 0 e $20 \%$ ao longo de $Y$; intensidade de deformação $\left(\overline{\mathcal{E}}_{\mathrm{s}}\right)$ entre 0,5 e 0,8 e forma dos elipsóides $(v)$ entre 0,09 e 0,56. Estes dados permitem estimar um elipsóide médio para toda a área analisada com a seguinte relação de eixos: 1,45: 1,1: 0,65, que corresponde ao estiramento de 45\% em X (horizontal NE-SW), de 10\% em Y (vertical) e encurtamento de $35 \%$ ao longo de Z (NW-SE). Este elipsóide geral (regional bulk strain) de deformação finita apresenta forma oblata $\left(\mathrm{K}_{\text {Flinn }}\right.$ de $0,38=$ achatamento geral), confirmando os resultados obtidos por Dayan \& Keller (1990) na Zona de Cisalhamento Paraíba do Sul nas vizinhanças de Três Rios (RJ). Os maiores valores de vorticidade $(0,51<\mathrm{Wk}<0.95)$ foram obtidos ao longo de zonas de cisalhamento secundárias, em afloramentos com foliação milonítica (Sm) e no Domínio Paraíba do Sul (DPS), enquanto valores menores $(0.15<\mathrm{Wk}<0.73)$, isto é, com predomínio de deformação coaxial, correspondem aos domínios Embu (DE), Juiz de Fora (DJF) e nas zonas de ocorrência de foliação gnáissica (Sn). A integração de valores de deformação cisalhante, entre as Zonas de Cisalhamento Rio Preto (ZCRP) e Paraíba do Sul (ZCPS), permitiu estimar rejeitos direcionais NE-SW próximos de $204 \mathrm{~km}$. Os resultados corroboram a observação geral de dois tipos de deformação na área: transcorrência dextral e encurtamento perpendicular às zonas de cisalhamento, materializado através de dobras simétricas e assimétricas, bem como achatamento dos agregados minerais. Em suma, pode-se dizer que o Cinturão Ribeira sofreu uma transpressão dextral, que foi acomodada através da partição da deformação entre estruturas contracionais NW-SE e transcorrentes NE-SW.

Agradecimentos Este artigo é parte da tese de doutoramento do primeiro autor, apresentada na UNESP/Rio Claro-SP, 
desenvolvida com auxílio financeiro concedido pela CAPES. Os autores agradecem, ainda, ao $\mathrm{CNPq}$, pelo apoio financeiro e concessão de bolsas de Iniciação Científica aos estudantes de geologia da UNESP/Rio Claro-SP. Os autores expressam agra- decimentos aos professores Marília Inês Mendes Barbosa e Fernando S. Moraes, à Maria de Fátima Silva Almeida e ao corpo consultivo da Revista Brasileira de Geociências, pelas sugestões e recomendações de revisão.

\section{Referências}

Almeida F.F.M. 1976. The system of continental rifts bordering the Santos basin, Brazil. An. Acad. Bras. Ciênc., 48(supl.):15-26.

Almeida J.C.H. 2000. Zonas de cisalhamento dúctil de alto grau do médio vale do Rio Paraíba do Sul. Tese de Doutoramento, Universidade Estadual Paulista, UNESP, Rio Claro/SP.

Almeida J.C.H., Silva L.G.E., Valladares, C.S. 1993. O Grupo Paraíba do Sul e rochas granitóides na região de Bananal-SP e Rio Claro-RJ: uma proposta de formalização litoestratigráfica. In: SBG, Simp. Geol. Sudeste,3, Atas, p. 155-160.

Almeida S.H.S. \& Ebert H.D. 2001. Estruturação tectônica e gravimetria do Cinturão Ribeira na região limítrofe entre os estados de São Paulo e Rio de Janeiro. In: SBG, Simpósio Nacional Estudos Tectônicos, 8, Atas, p. 37-40.

Berthé D., Choukroune P., Jegouzo P. 1979. Orthogneiss, mylonite and non-coaxial deformation of granite: the example of the South Armonican shear zone. J. Struct. Geol., 1: 31-42.

Braga I.F. \& Ebert H.D. 1998. Arcabouço estrutural e deformação da porção central da Cunha de Guaxupé -MG. Geociências, 17:399420.

Brandalise L.A., Ribeiro J.H., Ferrari P.G. 1976. Projeto Vale do Paraíba do Sul. DNPM/CPRM, Belo Horizonte, Relatório Técnico DGM, 2595, $411 \mathrm{p}$.

Campanha G.A.C. 1981. O lineamento de Além-Paraíba na área de três Rios (RJ). Revista Brasileira de Geociências, 11:159-171.

Campanha G.A.C. \& Sadowski G.R. 2002. Determinações da deformação finita em metassedimentos da Faixa Ribeira na região de Iporanga e Apiaí, SP. Revista Brasileira de Geociências, 32:107-118.

Castro H.O., Rocha R.L.S., Sperling E.V., Baltazar O.F. 1984. Geologia das folhas Mangaratiba, Ilha Grande, Cunhambebe, Angra dos Reis, Rio Mambucaba/Campos de Cunha, Parati, Cunha, Picinguaba e Juatinga -RJ. In: SBG, Cong. Brasileiro de Geololigia, 33, Anais, p. 2365-2367.

Dayan H. \& Keller J. V. A. 1990. A zona de cisalhamento do Rio Paraíba do Sul nas vizinhanças de Três Rios (RJ): uma análise da deformação dada por algumas feições estruturais. Revista Brasileira de Geociências, 19: 494-506.

Dehler N. M. \& Silva P. C. S. 1999. Projeto integração geológica folha Volta Redonda, 1999. Carta geológica SF.23-Z-A, escala 1:250.000. Programa levantamentos geológicos básicos do Brasil - PLGB, Companhia de Pesquisa e Recursos Minerais - CPRM.

Dias Neto C. M., Tassinari C. C. G., Egydio Silva M. 1995. Idades $\mathrm{Rb}-\mathrm{Sr}$ das rochas da região de Bananal - SP. Boletim IG-USP Série Cientifica, 26:59-68.

DRM, 1983. Projeto carta geológica do Rio de Janeiro. Folhas: Mangaratiba, Ilhas Grande, Cunhambebe, Angra dos Reis, Rio Mambucaba, Campos de Cunha, Picinguaba e Joatinga. DRM, Niterói.

Ebert H.D. \& Hasui Y. 1998. Transpressional tectonics and strain partitioning during oblique collision between three plates in the Precambrian of southeast Brazil. In: Holdsworth, R.E., Strachan, R.A \& Dewey, J.F. (eds.) Continental Transpressional and Transtensional Tectonic. Geological Society, London, Special Publications, 135, pp.: 231-252.

Erslev E. 1993. Instrain v. 3.02 - Strain analysis program. Depart. Of Earth Resources, CSU, By. Fort Collins, Colorado, USA.

Fiori A.P. 1997. Introdução à análise da deformação. Editora UFPR, Curitiba, 249 p.

Fonseca M. J. G. 1998. Mapa Geológico do Estado do Rio de Janeiro, escala 1:400.000. Programa cartas de síntese e estudos de integração geológica. DNPM - Brasília, 141p.

Fonseca M. J. G., Silva Z.C.G., Campos D.A., Tosatto P. 1979. Carta Geológica do Brasil ao Milionésimo (Folhas de Rio de Janeiro/Vi-
tória/Iguape, $S F-23 / 24$ e SG-23): texto explicativo. RADAMBRASIL, Brasília, 240p.

Fossen H., Tikoff B., Teyssier C. 1994. Strain modeling of transpressional and transtensional deformation. Norsk geologisk Tidsskrift, 74: 134-145.

Hanmer S. \& Passchier C. W. 1991. Shear-sense indicators: a review. Geol. Surv. of Canada, Paper 90-17, 72p.

Hasui Y., Ponçano W.L., Bistrichi C.A., Stein D.P., Galvão C.A.C.F., Gimenez A.F, Almeida M.A., Pires Neto A.G., Melo M.S., Santos M.C.S.R. 1977. Geologia da região administrativa 3 (Vale do Paraíba) e parte da região administrativa 2 (litoral) do Estado de São Paulo. IPT, São Paulo, 78p.

Heilbron M. 1993. Evolução tectono-metamórfica da Seção Bom Jardim de Minas (MG) - Barra do Piraí (RJ). Setor Central da Faixa Ribeira. Tese de Doutoramento, Instituto de Geociências, Universidade de São Paulo, São Paulo, 268p.

Heilbron M., Valeriano C., Tupinambá M., Almeida J.C.H. 1999. An evolutionary tectonic model for the central segment of Ribeira Belt: from the transamazonian collage to Gondwana amalgamation. In: SBG, Simp. Nac. Est. Tect,7, Atas, 2, p. 58-61.

Heilbron M., Valeriano C.M.,Valladares C.S., Machado N. 1995. A orogênese brasiliana no segmento central da faixa Ribeira, Brasil. Revista Brasileira de Geociências, 25:249-266.

Heilbron M., Mohriak W.U., Valeriano C.M., Milani E.J., Almeida J., Tupinambá M. 2000. From collision to extension: the roots of the southeastern continental margin of Brazil. In: Mohriak, W. \& Tankard, (eds.). Atlantic rifts and continental margins. Geophysical monograph, 115. American Geophysical Union, p. 1-32.

Holcombe R.J. 1999. Strain calculator, Ghoshflow: Programs to calculate and model strain, shear and vorticity parameters. Disponível em: http//: www. earthsciences.uq.edu.au. University of Queensland, Australia. Department of Earth Sciences.

Hossack J. R. 1968. Pebble deformation and thrusting in the Bygdin area (S. Norway). Tectonophysics, 5:315-339.

Hsu K.J. 1966. The characteristics of coaxial and non-coaxial strain paths. J. Strain Anal., 1:216-222.

Jain A. K. \& Anand A. 1988. Deformational and strain patterns of an intracontinental collision ductile shear zone - an example from Higher Garhwal Himalaya. J. Struct. Geol., 10:717-734.

Lisle R.J. 1985. Geological strain analysis. Pergamon Press Oxford, $76 \mathrm{p}$.

Machado N., Valladares C.M., Heilbron M., Valeriano C.S. 1996. U-Pb geochronology of the central Ribeira Belt (Brazil) and implications for the evolution of the Brazilian Orogeny. Precambrian Research, 79:347-361.

Machado R., Demange M., Mcreath I., Moutte J. 2000. Crustal zoning of neoproterozoic pre-collisional granitoid in the Paraíba do Sul Belt, Rio de Janeiro, Brazil. Revista Brasileira de Geociências, 30:70-73.

Machado R. \& Endo I. S. 1994. Superposição cinemática Brasiliana no cinturão de cisalhamento Atlântico e na Cunha de Guaxupé. In: SBG, Cong. Bras. Geol., 38, Anais, p. 269-270.

Machado, R. 1984. Evolução geológica, análise estrutural e metamórfica da região de Vassouras e Paracambi, porção ocidental do Estado do Rio de Janeiro. Tese de Doutoramento, Instituto de Geociências, Universidade de São Paulo, São Paulo, 196 p.

Machado Filho L., Ribeiro S.R., Gonzales C.A., Schenini A., Santos Neto A., Palmeira R.C., Pires J.L., Teixeira W., Castro H.E.F. 1983. Geologia. Rio de Janeiro/Vitória. Projeto RADAMBRASIL: levantamento de recursos naturais, Volume 32, Folhas SF. 23/24, 775 p.

Mello M.S., Riccomini C., Hasui Y., Almeida F.F.M., Coimbra A.M. 
1985. Geologia e evolução do sistema de bacias tafrogênicas continentais do sudeste do Brasil. Revista Brasileira de Geociências, 15: 193-201.

Nummer A. R. 2001. Geometria e cinemática de alojamento do maciço granítico de Arrozal, sudoeste do Estado do Rio de Janeiro. Tese de Doutoramento, Instituto de Geociências, Universidade de São Paulo, São Paulo, 169 p.

Ramsay J. G. \& Graham R. H. 1970. Strain variations in shear belts. Can. J. Earth Sci., 7: 786-813.

Ramsay J. G. \& Huber M. I. 1983. The techniques of modern structural geology: strain analysis. Academic Press, London, Vol.1, 700 p.

Ramsay J. G. 1967. Folding and fracturing of rocks. Mc-Graw-Hill, New York, $568 \mathrm{p}$.

Riccomini C., Appi C.J., Freitas E.L., Arai M. 1987. Tectônica e sedimentação no sistema de rifts continentais da Serra do Mar (Bacias de Volta Redonda, Resende, Taubaté e São Paulo). In: SBG, Simpósio Regional RJ-SP, 1, Anais, p. 253-272.

Ring U. 1998. Volume strain, strain type and flow path in a narrow shear zone. Geol. Rundsch, 86: 786-801.

Sanderson D. J. \& Marchini W. R. D. 1984. Transpression. Journal Structural Geology, 6: 449-458.

Sollner F. \& Trouw R. A. J. 1997. The Andrelândia depositional cycle (Minas Gerais), a post-tranzamazonic sequence South of São Francisco craton: evidence from U-Pb dating on zircons of a metasediment. Journal of South American Earth Science, 10: 21-28.

Tassinari C.C.G. \& Sato K. 1996. Idades de formação de crosta continental na parte sudeste do Estado de São Paulo com base em dados
Sm-Nd. In: SBG, Cong. Bras. Geol., 39, Salvador, Anais, p. 489492.

Tikoff B. \& Fossen H. 1993. Simultaneous pure and simple shear: the unifying deformation matrix. Tectonophysics, 217: 267-283.

Tikoff B. \& Fossen H. 1995. Limitations of three-dimensional kinematic vorticity analyses. J. Struct. Geol., 17: 1771-1784.

Trouw R.A., Heilbron M., Ribeiro A., Paciullo F., Valeriano C. M., Almeida J.C.H., Tupinambá M., Andreis, R.R. 2000. The central segment of the Ribeira Belt. In: U.G. Cordani, E.J. Milani, A. Thomaz Filho, D.A. Campos, (eds.) Tectonic evolution of South America. Rio de Janeiro, 31 st International Geological, p. 287-310.

Trouw R.A., Ribeiro A. \& Paciullo F.V.P. 1983. Geologia estrutural dos Grupos São João Del Rei, Carrancas e Andrelândia, sul de Minas Gerais. Academia Brasileira de Ciências, 55: 71-85.

Tupinambá M., Heilbron M., Oliveira A., Pereira A.J., Cunha E.R.S.P., Fernandes G.A., Ferreira F.N., Castilho J.G., Teixeira W. 1996. Complexo Rio Negro - uma unidade estratigráfica relevante no entendimento da evolução da Faixa Ribeira. In: Congr. Bras. Geol., 39, Anais, p. 481.

Weber K. 1986. Metamorphism and crustal rheology - implications for the structural development of the continental crust during prograde metamorphism. In: Dawson et al. (eds) - The nature of lower continental crust. Geological Society Special Publication, 24, p.95-106.

Manuscrito A-1584

Revisão aceita em 7 de agosto de 2006 